\title{
MiR-21-3p regulation FGFR1/FGF21/PPARY pathway induces atrial fibrosis by targeting FGFR1 in diabetes
}

Jun Gu ( $\sim$ gjforsub@163.com )

Shanghai ninth people's hospital, Shanghai Jiao Tong University School of Medicine https://orcid.org/0000-0002-1847-7304

Jian-an Pan

Shanghai ninth people's hospital, Shanghai jiaotong university school of medicine Jian-ying Yu

Shanghai ninth people's hospital, Shanghai jiaotong university school of medicine

Hao Lin

Shanghai ninth people's hospital, Shanghai jiaotong university school of medicine

\section{Hui-li Zhang}

Shanghai ninth people's hospital, Shanghai jiaotong university school of medicine

Jun-feng Zhang

Shanghai ninth people's hospital, Shanghai jiaotong university school of medicine

Chang-qian Wang ( $\nabla$ wcqnine@163.com)

Shanghai ninth people's hospital, Shanghai jiaotong university school of medicine

\section{Original investigation}

Keywords: atrial fibrosis, diabetes mellitus, microRNA, epicardial adipose tissue, browning

Posted Date: April 6th, 2020

DOI: https://doi.org/10.21203/rs.3.rs-20602/v1

License: (a) (1) This work is licensed under a Creative Commons Attribution 4.0 International License. Read Full License 


\section{Abstract}

Background A relationship between the abundance of epicardial adipose tissue (EAT) and the risk of atrial fibrillation (AF) in diabetes mellitus (DM) has been reported. And browning of EAT might be a novel approach for prevention or treatment in AF by adjusting atrial fibrosis. MicroRNA-21 (miR-21) is one of the most important miRs, and previous studies have shown that it is a regulatory factor in atrial fibrosis and AF. The aim of this study was to examine the role of different subtypes of miR-21 in EAT browning and atrial fibrosis under hyperglycemia conditions. Methods The expression of serum hsa-miR-21-3p and hsa-miR-21-5p in patients with DM and/or AF were determined by quantitative reverse transcriptionpolymerase chain reaction. And normal C57BL/6 wild type (WT) and miR-21 knockout (KO) mice were used to establish the diabetic model by intraperitoneal injection of streptozotocin (STZ). In vitro, The EAT adipocytes from miR-21 KO mice were cultured and transfected with miR-21-3p mimic or miR-21-5p mimic and co-cultured with atrial fibroblasts in both HG or LG conditions. The browning of EAT and the fibrosis of fibroblasts were assessed by western blotting, immunofluorescence, Masson staining, and ELISA. Finally, the gain- and loss-of-function experiments were used to identified fibroblast growth factor receptor 1 (FGFR1) as the target gene of miR-21-3p, and the regulatory pathway of miR-21-3p FGFR1, fibroblast growth factor 21 (FGF21) and peroxisome proliferator-activated receptor gamma (PPARY) that controlled EAT browning and participates the process of hyperglycemia-induced atrial fibrosis. Results In patients with DM and/or AF, serum hsa-miR-21-3p, instead of hsa-miR-21-5p, was significantly upregulated. And miR-21 KO clearly ameliorated the atrial fibrosis in the diabetic mice. miR-21-3p as a key regulator that controls EAT browning and participates in atrial fibrosis under hyperglycemia conditions. Moreover, our gain- and loss-of-function experiments showed that FGFR1, as a direct target of miR-21-3p identified a regulatory pathway in EAT adipocytes consisting of miR-21-3p, FGFR1, FGF21 and PPARY. Conclusions MiR-21-3p regulated EAT browning and participates the process of hyperglycemia-induced atrial fibrosis by targeting FGFR1/FGF21/PPARy pathway.

\section{Background}

Diabetes mellitus (DM), despite many treatments, remains a major public health problem that currently affects more than 425 million people worldwide[1]. Due to the long-lasting rise of blood glucose, DM can cause many complications to affect the cardiovascular system, kidneys, retina, nervous system, etc[2]. Atrial fibrillation (AF), the most common arrhythmia in clinical practice, confers a major cause of morbidity and mortality due to an increased risk of abnormal hemodynamics and thromboembolism[3]. DM, whether type 1 or type 2, according to a large number of clinical studies[4-6], has been shown to be a significant promoter for AF, with the mechanisms of atrial structural and electrical remodeling[7]. The extensive atrial fibrosis is a hallmark of $\mathrm{AF}$ and is considered to play an important role in both initiating and perpetuation AF under hyperglycemia conditions[7].

Epicardial adipose tissue (EAT), a metabolically active visceral fat reservoir surrounding and infiltrating myocardium and vessels, is recognized as a source of pro-inflammatory mediators involved in the onset and development of various cardiovascular diseases (CVD), such as coronary artery disease (CAD) and 
arrhythmias[8, 9]. And the increase in EAT volume or thickness is associated with DM and is correlated with left atrial enlargement, atrial fibrosis, abnormal electrical conduction between cardiomyocytes, and results in the onset of $A F[10,11]$.

As with other adipose tissue, EAT is also made up of both white adipose tissue (WAT) and brown adipose tissue (BAT) and presents the potential for trans-differentiation from BAT into WAT, or vice versa[12]. Compared with less metabolically active WAT depots, BAT is characterized by an abundance of mitochondria, capillaries, and uncoupling protein-1 (UCP-1). BAT is thought to play a protective role against cardiometabolic dysfunction by virtue of its role in non-shivering thermogenesis[13]. And browning of WAT might be a novel approach for prevention or treatment in CVD[13]. To date, WAT browning is thought to be impaired in DM[14]. And the mechanisms of EAT browning and its role in DMinduced atrial fibrosis remains to be elucidated.

Fibroblast growth factor 21 (FGF21) has significant effects on energy balance, glucose metabolism, and lipid metabolism[15]. It was originally reported that FGF21 identified the liver as its main source[16]. In the subsequent studies, its role in inducing the browning of WAT is slowly emerging[17]. The biological roles of FGF21 are affected through downstream signaling pathways by binding to fibroblast growth factor receptors (FGFRs) and proliferator-activated receptor gamma (PPARY) activation[18]. And FGFR1 has been shown to mediate the regulation of FGF21 in WAT.

MicroRNAs (miRNAs) are a class of endogenous, 20-22-nucleotide non-coding RNAs. Their main function is to regulate post-transcriptional regulation of target genes expression by binding to the 3 ' untranslated region (3'-UTR)[19]. MicroRNA-21 (miR-21) has been shown to be associated with atrial fibrosis in previous studies[20-22]. But most of its mechanisms focused on the damage of cardiomyocytes and the activation of fibroblasts. Few reports have shown the relationship between miR-21 and the browning of epicardial adipose tissue. Since miR-21 is abundantly expressed in EAT and FGFR1 has potential miR-213p-binding sites in the 3'UTR, in this work, we identify miR-21-3p (the subtype of miR-21 family) as a key regulator that controls EAT browning and participates atrial fibrosis under hyperglycemia conditions. Moreover, FGFR1, as a direct target of miR-21-3p, is decreased in these conditions and controls WAT to BAT differentiation trough FGFR1/FGF21/PPAPY.

\section{Methods}

\section{Animal experiments}

All animal procedures were performed in accordance with the Guide of US National Institutes of Health for the Care and Use of Laboratory Animals and were approved by the Institutional Animal Care and Use Committee at Shanghai ninth people's hospital of Shanghai Jiaotong University School of Medicine, China. All mice used for these studies were on the C57BL/ 6 genetic background. Male wild-type and miR21 knockout (KO) mice, purchased from Shanghai Model Organisms Center (Shanghai, China), aged 8 to 10 weeks, were used in the studies. Mice were assigned to one of four groups randomly: saline-treated 
WT group, STZ-treated WT group, saline-treated miR-21 KO group, and STZ-treated miR-21 KO group. WT mice and miR-21 KO mice were both infused with $150 \mathrm{mg} / \mathrm{kg}$ streptozotocin (STZ) or an equivalent volume of saline as a bolus intraperitoneally, and the blood glucose level was checked after 7 days. Mice with blood glucose levels of $16.7 \mathrm{mM}$ were considered to be diabetic and used for the experiments in STZ-treated groups, with each group contained 6 mice. The blood glucose levels of each group were shown in supplementary material Table S1

\section{MiR-21 WT/KO mouse EAT pre-adipocytes culture and differentiation}

The mouse pre-adipocytes isolation was performed as previously described[23]. In brief, EAT was isolated under sterile conditions, washed twice in phosphate buffered solution (PBS) supplemented with $1 \%$ penicillin/streptomycin and then minced into $1 \mathrm{~mm}^{3}$ pellets. Enzymatic digestion was performed with $2 \mathrm{mg} / \mathrm{ml}$ collagenase II (Worthington Biochemical, USA) at $37^{\circ} \mathrm{C}$ in the water bath for $1 \mathrm{~h}$ with gentle agitation and terminated by the same volume of DMEM/F12 (Hyclone, USA) supplemented with 10\% fetal bovine serum (FBS). The suspension was filtered on a $75 \mu \mathrm{m}$ nylon cell strainer and centrifuged at 2000 $\mathrm{r} / \mathrm{min}$ for $5 \mathrm{~min}$. After disposing of the red blood cell lysed solution, the suspension was centrifuged at $2000 \mathrm{r} / \mathrm{min}$ for $5 \mathrm{~min}$ again and the pre-adipocytes were re-suspended in DMEM/F12 supplemented with $10 \%$ FBS and diluted to a final concentration of $10^{6}$ cells $/ \mathrm{ml}$. These cells were cultured at $37^{\circ} \mathrm{C}$ in a humidified atmosphere containing $5 \% \mathrm{CO}_{2}$. Hereafter, EAT pre-adipocytes isolated from WT mice and miR-21 KO mice were induced to differentiate into mature adipocytes as fellows when reached $80 \%$ confiuence. Cells were incubated with $0.25 \mu \mathrm{M}$ dexamethasone, $0.5 \mathrm{mM}$ 3-Isobutyl-1-methylxanthine and $10 \mu \mathrm{g} / \mathrm{ml}$ insulin for 3 days, then thoroughly rinsed with culture media and incubated for an additional 3-4 days with $10 \mu \mathrm{g} / \mathrm{ml}$ insulin. Differentiation was confirmed by morphological changes, including intracellular lipid droplet accumulation, as confirmed by microscopic observation. Then mature adipocytes treated with low glucose (LG) (5.5 mM) and high glucose (HG) (30 mM) for 72 h.

\section{Oil Red 0 Staining}

Cultured adipocytes were washed with PBS and fixed with 4\% formaldehyde at room temperature for $15 \mathrm{~min}$. Then the cells were stained with the Oil Red $\mathrm{O}$ working solutions containing $6 \mathrm{ml}$ Oil Red 0 stock solution ( $5 \mathrm{~g} / \mathrm{l}$ in isopropanol) and $4 \mathrm{ml}$ ddH2O for $20 \mathrm{~min}$. After staining, the cells were washed with $60 \%$ isopropanol in PBS and observed using an Olympus TH4-200 microscope (Japan). And the Oil Red signals were quantified by measuring the optical density at $490 \mathrm{~nm}$.

\section{Cell transfection and infection}

When the mouse pre-adipocytes reached $80 \%$ confluence, the lentiviral vectors carrying the miR-21-3p mimics, miR-21-5p mimics, miR-21-3p inhibitors, FGFR1 shRNA (5'-TGTAACCTCTTCTTCCTAGGTC-3'), pcDNA-FGFR1 (F: CCGCTCGAGGGCCATCGGGCTGGATAAG; R: CCGGAATTTGGGGACAGGGTTGGTAG) or negative control (NC) gene were added into the cells. After transfection for $24-48 \mathrm{~h}$, the expression of the green fluorescent protein was observed under the fluorescence microscope. 


\section{Isolation and culture of adult mouse atrial fibroblasts}

The experimental procedure to isolate adult mouse atrial fibroblasts was performed as we previously described[24]. In brief, the hearts from 8-10 weeks old male C57BL/6 mice were rapidly excised and submerged in cold phosphate buffered saline. The atria were cut into pieces with a tissue chopper. The pieces were washed and cells were dissociated with $1 \mathrm{mg} / \mathrm{ml}$ collagenase II (Worthington Biochemical, USA). After $30 \mathrm{~min}$ at $37^{\circ} \mathrm{C}$, tissue pieces were discarded, and the supernatant, containing the isolated cells, was centrifuged at $1500 \mathrm{r} / \mathrm{min}$ for 5 min. Cells were resuspended in DMEM containing $10 \% \mathrm{FBS}$, and the resulting cell mixture was pre-plated in a $5 \% \mathrm{CO} 2$ incubator at $37^{\circ} \mathrm{C}$ for $90 \mathrm{~min}$. After removal of the myocyte-enriched medium, DMEM was then added to the pre-plated fibroblasts, which were cultured for 3-4 days before being passaged. These cultured cells were also characterized as we previously described[24].

\section{Co-culture of atrial fibroblasts and adipocytes}

Atrial fibroblasts and EAT fully-differentiated adipocytes were co-cultured using transwell inserts with a $0.4-\mu \mathrm{m}$ porous membrane, which separated the adipocytes $\left(5.0 \times 10^{5} \mathrm{cells} /\right.$ well $)$ in the lower chamber from the fibroblasts $\left(5.0 \times 10^{5}\right.$ cells/well) cells in the upper chamber. Each cell type was grown independently on the transwell plates. The hanging insert is constructed with a membrane having pores that are large enough to permit the passage of small molecules, yet small enough to prevent the passage of even the most motile of cell types. Following co-culture for $72 \mathrm{~h}$ after the incubation period, the biomarkers of adipocytes browning and fibrosis-related gene expressions were measured in adipocytes and fibroblasts, respectively. The co-culture of atrial fibroblasts and adipocytes were treated with low glucose (LG) $(5.5 \mathrm{mM})$ and high glucose $(\mathrm{HG})(30 \mathrm{mM})$ for $72 \mathrm{~h}$ in a humidified atmosphere containing $5 \% \mathrm{CO}_{2}$ at $37^{\circ} \mathrm{C}$.

\section{Histology, immunohistochemical staining, and immunofluorescence staining}

EAT or atrial tissues from mice were fixed with 10\% phosphate-buffered formalin for $24 \mathrm{~h}$. Fixed tissues were then paraffin-embedded and serially sectioned with a microtome ( $4 \mu \mathrm{m}$ thickness). The extent of interstitial fibrosis was evaluated by Masson staining. Immunohistochemical staining for collagen I, collagen III, alpha-smooth muscle actin ( $\mathrm{a}-\mathrm{SMA}$ ), transforming growth factor-beta (TGF- $\beta$ ) and UCP-1 in

atrial or EAT sections were also performed. Immunofluorescence staining of UCP-1 was performed in vitro cultured adipocytes. Images were acquired and analyzed by Image-Pro Plus 6.0.

\section{Western blotting analysis}

The protein samples extracted from atrial tissue, EAT, adipocytes and atrial fibroblasts were subjected to sodium dodecyl sulfate-polyacrylamide gel electrophoresis and transferred to a polyvinylidene difluoride membrane. Membranes were blocked with TBST containing 5\% milk and incubated with the different primary antibodies as indicated overnight at $4{ }^{\circ} \mathrm{C}$ : GAPDH mouse polyclonal antibody (1:5000, 60004-1-lg, Proteintech), TGF- $\beta 1$ rabbit polyclonal antibody (1:1000, ab92486, Abcam), CTGF rabbit polyclonal 
antibody (1:1000, ab6992, Abcam), Collagen I rabbit polyclonal antibody (1:1000, ab34710, Abcam), Collagen III rabbit polyclonal antibody (1:1000, ab7778, Abcam), UCP-1 rabbit monoclonal antibody (1:1000, ab209483, Abcam), FGFR1 rabbit polyclonal antibody (1:1000, ab10646, Abcam), FGF21 rabbit monoclonal antibody (1:1000, ab171941, Abcam) and PPARy rabbit polyclonal antibody (1:1000, ab45036, Abcam). The membranes were then incubated with horseradish peroxidase-conjugated secondary antibodies and visualized using the enhanced chemiluminescence system. Densitometric analysis was performed using Scion Image software (USA).

\section{RNA preparation and analysis}

Total RNA was extracted from EAT and adipocytes using the TRIzol reagent (Invitrogen, USA). Reversetranscribed into cDNA using PrimeScript ${ }^{\text {TM }}$ RT reagent Kit (Takara, Japan). Next, the cDNA was quantitatively amplified using TB Green Premix Ex Taq II (Takara, Japan). Real-time PCR was conducted in triplicate using an Applied Biosystems 6Flex. The sequences of the forward and reverse primers used for amplification are shown in supplementary material Table S2. The results for the expression of FGFR1 and UCP1 were presented relative to the expression of the GAPDH gene and relative miR-21 expression was normalized to the expression of U6 small nuclear RNA (snRNA) by the Delta-Delta Ct method.

\section{ELISA test for inflammatory cytokines}

Murine tumor necrosis factor alpha (TNF-a), interleukin 6 (IL-6) and monocyte chemoattractant protein 1 (MCP-1) levels in co-culture supernatants were measured by ELISA assay (TNF-a: ab208348; IL-6: ab100712; MCP-1: ab246547; Abcam, USA) according to the manufacturer's directions.

\section{Patients and serum miRNAs measurements}

The current prospective study was approved by the Research Ethics Committee of Shanghai ninth people's hospital of Shanghai Jiaotong University, China. Written informed consent was obtained from all of the patients enrolled. All serum samples were handled and made anonymous according to ethical and legal standards. A total of 80 patients were enrolled from 2016 to 2017 in our department, including patients diagnosed with DM (20 patients), AF (20 patients), DM and AF (20 patients), and another 20 patients as health control. Patients diagnosed as having DM based on the criterion of the American Diabetes Association[25] and AF based on AHA/ACC/HRS guideline[26]. Patients with any inflammatory disease, renal or hepatic impairment, neoplastic disorders, recent stroke ( $<3$ months), heart failure, angina pectoris, or myocardial infarction were excluded. Serum samples were collected at the time of primary diagnosis. All serum samples were immediately processed and separated, then aliquoted and stored at $-80^{\circ} \mathrm{C}$ prior to use. miRs were isolated from serum samples using miRNeasy ${ }^{\mathrm{TM}} \mathrm{RNA}$ isolation kit (Qiagen, USA) according to the manufacturer's instructions. For analysis of miRNA expression, real-time q-PCR analyses were carried out using SYBR Green Reagents (Applied Biosystems, USA) according to the manufacturer's instructions. Cel-miR-39 was used as external control.

\section{Statistical analysis}


Statistical analysis was performed by using SPSS 22.0 software. All arithmetic data were presented as mean $\pm S D$ at least three independent experiments. And qualitative variables were given as frequency and percentage (\%). For quantitative variable analysis, t-test and one way ANOVA test, if appropriate, were used. A two-sided chi square test was used to compare qualitative variables. A value of $P<0.05$ was considered statistically significant.

\section{Results}

\section{MiR-21 participated in atrial fibrosis and EAT browning in mouse DM model}

As exhibited in Fig. 1, compared to the control group, DM induced a significant atrial interstitial collagen deposition, and this change was significantly attenuated by miR-21 KO (Fig. 1a-1b). Besides, DM induced an increased expression of fibrosis-related proteins, such as TGF- $\beta 1$, CTGF, Collagen I, collagen III and aSMA in atrial tissue, which were also markedly alleviated by miR-21 KO (Fig. 1c-1e). More interestingly, both the level of miR-21 and miR-21-3p were rise after STZ treatment in WAT of WT or miR-21 KO mice (Fig. 2a-2b). Hyperglycemia conditions resulted in a decreased expression of WAT browning biomarker (UCP-1), which was significantly reversed in miR-21 KO mice (Fig. 2c-2d). Furthermore, we evaluated the WAT browning associated proteins and found that FGFR1, FGF21, and PPARY expressions were decreased in diabetic model and were partly reversed by miR-21 KO (Fig. 2e).

\section{MiR-21-3p played a major role in browning of EAT}

We investigated the expression of different miR-21 subtypes in various clinic conditions, including healthy control, DM, AF, DM, and AF. Table 1 demonstrates the demographic and baseline characteristics of enrolled patients. And the result showed that the expression of serum hsa-miR-21-3p, instead of hsamiR-21-5p, was significantly increased in patients with DM and/or AF (Fig. 3a). The Oil Red staining of mature adipocytes was performed after differentiation induction of the EAT pre-adipocytes from WT or miR-21 KO mice (Fig. 3b). Hereafter, the result of PCR showed that miR-21-3p, rather than miR-21-5p, was significantly increased in mature adipocytes differentiated from EAT pre-adipocytes of WT mice after glucose treated (Fig. 3c). For further proof, the isolated EAT pre-adipocytes from miR-21 KO mice transfected with mimics NC, miR-21-3p mimics or miR-21-5p mimics to achieve the overexpression of the corresponding miR-21 subtype (Fig. 3d) and then induced to differentiate into mature adipocytes. The results of Western blotting and immunofluorescence showed that UCP-1 expression was significantly inhibited by miR-21-3p mimics rather than miR-21-5p mimics transfection (Fig. 3e-3f) which indicated that miR-21-3p was involved in EAT browning.

\section{MiR-21-3p inhibited browning of EAT to promote hyperglycemia-induced atrial fibrosis}

EAT pre-adipocytes from miR-21 KO mice transfected with mimics NC, miR-21-3p mimics or miR-21-5p mimics, and then induced to differentiate into mature adipocytes. Full-differentiated adipocytes co- 
cultured with atrial fibroblasts from WT mice and were treated with low glucose (LG) (5.5 mM) and high glucose $(\mathrm{HG})(30 \mathrm{mM})$ for $72 \mathrm{~h}$. We observed that hyperglycemia conditions induced a significantly higher expression of fibrosis-related proteins in fibroblasts (Fig. 4a-4b). Besides, under the same hyperglycemic conditions, miR-21-3p transfected adipocytes resulted in an up-regulated expression of fibrotic proteins in fibroblasts compared with mimics NC or miR-21-5p mimics transfected adipocytes (Fig. 4a-4b). We also determined the inflammatory factor in co-culture supernatants, including TNFa, IL-6, and MCP-1, and the results indicated that these inflammatory factors were markedly increased by miR-21-3p mimics transfection into adipocytes instead of mimics NC or miR-21-5p mimics in both LG and HG conditions (Fig. 4c). At last, the same trend in WAT browning biomarker, UCP1 expression, was also observed (Fig. 4d-4e). The aforementioned results indicated that miR-21-3p might be involved in EAT browning and participate in hyperglycemia-induced atrial fibrosis. At the same time, EAT pre-adipocytes from miR-21 WT mice transfected with mimics NC, miR-21-3p mimics were implemented which showed the same result in corresponding experiments (Figure S1).

\section{MiR-21-3p regulated FGFR1/FGF21/PPARy to participate in browning of EAT by targeting FGFR1}

Analysis of the databases Mirdb () and TargetScan () showed that FGFR1 was a potential target gene of miR-21-3p. The matching positions for miR-21-3p within 3区-UTR of the targeted FGFR1 mRNA are shown in Fig. 5a. The dual-luciferase assay demonstrated that miR-21-3p reduced the luciferase activity (Fig. 5b). Moreover, Pre-adipocytes from WT mice transfected with mimics NC, miR-21-3p mimics, inhibitor NC, and miR-21-3p inhibitor and then induced to differentiate into mature adipocytes. mRNA and protein expression of FGFR1 was decreased in cells with overexpression of miR-21-3p mimic and increased in cells overexpression of miR-21-3p inhibitors (Fig. 5c-5d). Then, pre-adipocytes from WT mice transfected with shRNA NC, FGFR1 shRNA, pcDNA-NC, pcDNA-FGFR1 and induced to differentiate into mature adipocytes. The expression of UCP1 decreased when FGFR1 shRNA transfected and upregulated after pcDNA-FGFR1 transfected both in mRNA level and protein level (Fig. $5 \mathrm{e}-5 \mathrm{~g}$ ). Based on this, preadipocytes from $21 \mathrm{KO}$ mice were transfected with mimics NC, miR-21-3p mimics, pcDNA-FGFR1, miR-21$3 p$ mimics + pcDNA-FGFR1 and induced to differentiate into mature adipocytes. The results showed that miR-21-3p efficiently suppressed UCP-1 expression in adipocytes by inhibiting FGFR1 through FGFR1/FGF21/PPARY pathway, which was partially reversed by upregulating FGFR1 through pcDNAFGFR1 transfected (Fig. 5h-5j).

\section{MiR-21-3p regulated WAT browning associated protein FGFR1/FGF21/PPARy to promote hyperglycemia-induced atrial fibrosis by targeting FGFR1}

EAT pre-adipocytes from miR-21 KO mice transfected with mimics NC, miR-21-3p mimics, pcDNA-FGFR1, miR-21-3p mimics + pcDNA-FGFR1, and then induced to differentiate into mature adipocytes. Mature adipocytes co-cultured with atrial fibroblasts from WT mice and were treated with LG (5.5 mM) and HG $(30 \mathrm{mM})$ for $72 \mathrm{~h}$. The results showed that $\mathrm{HG}$ condition led to efficiently increased expression of fibrotic 
proteins in fibroblasts compared with LG condition (Fig. 6a-6b). Besides, under the same conditions, miR21-3p transfection into adipocytes resulted in higher expressions of fibrotic protein compared with mimics NC and pcDNA-FGFR1 transfected could partially reverse this phenomenon (Fig. 6a-6b).

Western blotting was also used to analyze FGFR1, FGF21, PPARy expression of adipocytes in our coculture model. If miR-21-3p mimic transfection into adipocytes, these EAT browning associated proteins were efficiently inhibited in adipocytes in HG condition compared with LG condition. Furthermore, under the same HG condition, miR-21-3p mimic transfection into adipocytes resulted in lower expressions of WAT browning associated proteins compared with mimics NC and pcDNA-FGFR1 transfected could partially reverse this phenomenon (Fig. 6c). Three inflammatory factors (TNFa, IL-6, and MCP-1) were markedly increased by miR-21-3p mimic transfection compared with mimics NC in both LG and HG conditions (Fig. 6d) and pcDNA-FGFR1 transfected could partially reverse this phenomenon. Finally, the WAT browning biomarker, UCP1, was markedly inhibited by miR-21-3p mimic and pcDNA-FGFR1 transfected could partially reverse this phenomenon (Fig. 6e-6f).

\section{Discussion}

In the current study, we further identified a regulatory pathway in EAT adipocytes consisting of miR-21-3p, FGFR1, FGF21 and PPARY that control EAT browning and participates the process of hyperglycemiainduced atrial fibrosis. Modulation of this signaling pathway might provide a therapeutic option for the prevention and treatment of atrial fibrosis in DM.

Numerous evidence has suggested that diabetes is a strong, independent risk factor for AF[7, 27]. The underlying mechanisms by which diabetes increases the susceptibility to AF are unclear but are thought to be associated with electrical and structural remodeling of the atria[28, 29]. Extensive atrial fibrosis resulting from hyperglycemia is thought to play a key role in both initiating and perpetuation AF as an increase of collagen deposition in the atria can cause abnormal conduction of signals, rupture of the propagating waves, and even the occurrence of re-entry[30]. In diabetic conditions, fibroblasts are activated leading to inappropriate collagen production and deposition no matter in type I DM[31,32] or type II DM[33-35]. Emerging evidence poses a unique challenge to understanding the pathogenesis of atrial fibrillation caused by diabetes, which is often consistent with obesity. Obesity leads to increased thickness of EAT and enhanced invasiveness, which in turn leads to interstitial fibrosis. Recent studies have reported a higher volume or thickness of EAT in patients with AF, particularly in those with nonparoxysmal AF[36-38]. Some studies have reported a relationship between left atrium size and EAT thickness or volume, which might contribute to atrial fibrosis or cardiomyocytes electrophysiological disorders leading to $A F[10,11,37]$. In particular, posterior left atrial adipose tissue is supposed to contribute to the atrial remodeling leading to the onset of AF[39]. Moreover, under diabetic or hyperglycemic conditions, high volume of thickness of EAT is also observed[40-42]. There are several possible mechanisms for the associations between EAT and the increased risks of AF. First, EAT is a rich source of adipokines and cytokines which have pro-fibrotic and pro-inflammatory effects, and the closed proximity of EAT to atrial cardiomyocytes might favor the paracrine activity of EAT secretome, which 
seems to play a role in the pathogenesis of $\mathrm{AF}[10]$. Second, adipocyte infiltration within atrial cardiomyocytes might lead to the loss of side-to-side cell connection with consequent reduced and heterogeneous voltage[43-45]. Third, the fibrotic remodeling of EAT was also associated with atrial myocardial fibrosis[10].

On the other hand, EAT is also made up of WAT and BAT. BAT is the primary site of non-shivering thermogenesis and is, therefore, a relevant site for adaptive energy expenditure processes. Compared with WAT, BAT improves insulin sensitivity, glucose tolerance, lipid homeostasis, and protects against the pathogenesis of $\operatorname{CVD}[13,46]$. It has been recently shown that adipose tissues have remarkable plasticity in relation to their contents of white and brown adipocytes. Modulation of the cardiac and vascular adipose tissue to increase the proportion of thermogenic brown or beige adipocytes might be a viable way to improve local inflammation and reduce cardiovascular risk[13,46]. However, under diabetic or hyperglycemic conditions, impaired WAT browning potential is observed[14], which might aggregate the pathogenesis of AF. Consistent with previous studies, our experiments indicated that hyperglycemia inhibited the biomarkers of BAT in mouse EAT as well as in vitro cultured adipocytes, suggesting that hyperglycemia might decrease the process of EAT browning.

To date, the mechanisms of EAT browning and its role in DM-induced atrial fibrosis remain to be elucidated. FGF21 has been shown to have a beneficial effect on metabolism and energy balance by enhancing fatty acid-oxidation during prolonged fasting and also by promoting WAT browning[47-50]. And a recent clinical study showed that cold exposure increased circulating levels of the fat browning activators FGF21 and irisin and that treatment with either of these endocrine regulators up-regulated browning genes and promoted thermogenesis[51]. Mechanistically, FGF21 activates cell signaling by binding to a heteromeric cell-surface receptor tyrosine kinase complex composed of $\beta$-Klotho and FGFR1 [49]. Both $\beta$-Klotho and FGFR1 are abundantly expressed in WAT, where FGF21-regulated genes are involved in a variety of metabolic processes including lipogenesis, lipolysis, fatty acid oxidation, and WAT browning[49]. Furthermore, PPARy, a member of the nuclear receptor family of ligand-activated transcription factors, is also required for adipocyte differentiation. PPARy agonist has been shown to induce browning of the EAT that probably contributes to the increase in lipid turnover[52]. And FGF21 was thought to be a key mediator of the physiologic and pharmacologic actions of PPARY in WAT[49]. FGF21 stimulates PPARy transcriptional activity and FGF21 deficiency mice have decreased PPARy activity in WAT and corresponding reductions in WAT mass and adipocyte size[49]. On the other hand, FGF21 was previously shown to be induced by PPARY agonists in WAT and to cooperate with rosiglitazone in promoting differentiation in 3T3-L1 adipocytes $[53,54]$. And obese, insulin-resistant mice lacking FGF21 are refractory to the actions of rosiglitazone, including both beneficial and adverse effects[49]. Therefore, we conclude that the actions of FGF21 and PPARY are fundamentally intertwined, and propose a feedforward regulatory model in WAT[55]. And FGFR1/FGF21/PPARy might be an important signal pathway to precipitate the browning of WAT. In our mouse diabetic model as well as in vitro cellular model, we found that FGFR1/FGF21/PPARy pathway was inhibited in EAT or under hyperglycemia conditions. Consistently, FGF21 was also shown to protect the blood-brain barrier through FGFR1/FGF21/PPARY activation, which up-regulated tight junction and adhesion junction proteins[56]. 
Recent studies indicated that miRs function as important regulators that participates in DM-induced atrial fibrosis[35]. The role of miR-21 in the pathogenesis of atrial fibrosis has been illuminated, and increased miR-21 expression was correlated positively with atrial fibrosis or fibrotic gene expression[20-22]. Many target genes of miR-21 have been found to play a large role in DM-induced atrial fibrosis through different biological pathways. Tao $\mathrm{H}$ et al. found that miR-21 regulated atrial fibrosis via dysregulation of WW Domain-Containing Protein 1[57]. Cao W et al demonstrated that the tumor suppressor cell adhesion molecule 1 was the potential target of miR-21, and miR-21 promoted cardiac fibrosis via STAT3 signaling pathway by decrease CADM1 expression[58]. In our mice diabetic model, we also found that miR-21 KO manifested a decreased atrial fibrosis as well as fibrotic gene expression. However, miR-21 has several subtypes, such as miR-21-3p and miR-21-5p in human, and miR-21-3p and miR-21-5p in mice. We further investigated the expression of different miR-21 subtypes in various clinic conditions, including healthy control, DM, AF, DM combined AF. And the results indicated that hsa-miR-21-3p, instead of hsa-miR-21-5p, was obviously increased in patients with DM and/or AF, suggesting that hsa-miR-21-3p is more likely to be involved in the regulation of DM-induced atrial fibrosis. Besides, emerging evidence indicates that miRs also function as important regulators in brown remodeling of adipocytes. Muscle-enriched miR133a directly down-regulated expression of the key transcriptional activator of brown fat differentiation, positive regulatory domain containing 16 (PRDM16), and cold exposure decreased miR-133a levels and promoted brown fat cell differentiation[59,60]. Brown adipocyte-enriched miR-155 was also shown to inhibit brown fat cell differentiation by directly targeting the browning transcription factor C/EBP[61]. But whether miR-21-3p played a role in the browning of EAT under diabetes and thus affected atrial fibrosis has not been studied. In the present study, we further identify miR-21-3p as a key regulator that controls EAT browning in hyperglycemia condition. Further, we predicted target genes by Targetscan and found browning transcription factor FGFR1 as its potential target. Besides, by virtue of in vitro co-culture model, miR-21-3p regulated fibrotic gene expression in atrial fibroblasts through affecting the adipocytes browning.

A paracrine effect of EAT on the neighboring myocardium has been proposed[10]. EAT produces a number of inflammatory mediators and adipocytokines that can modulate the functional and structural properties of the myocardium $[62,63]$. In this line, it has been shown that the secretome of EAT can induce atrial fibrosis, an important determinant of the substrate of AF. In the present study, we observed that miR21-3p mimics for adipocytes could increase the levels of inflammatory factors in co-culture model in hyperglycemia conditions.

Our current study has some limitations that deserve to be mentioned. First, mouse adipocyte-specific miR21-3p KO was not performed in this study. Second, we did not conduct in vivo intervention experiments to study the correlation between miR-21-3p and EAT browning. Third, we only determined the extent of atrial fibrosis, however, we did not perform the experiments of cardiac electrophysiology and programmed stimulation, such as inducibility of AF.

\section{Conclusions}


In this study, we show that miR-21-3p under hyperglycemia conditions acts as an inhibitor of EAT browning and participates in the process of atrial fibrosis. Mechanistically, we show that down-regulation of miR-21-3p increased expression of the FGFR1, contributing to the activation of the browning transcriptional program via FGFR1/FGF21/PPARY. Importantly, in addition to fat browning in EAT, antimiR-21-3p-mediated beneficial effects, including decreased inflammatory factors, inhibited fibrosisrelated gene expression in atrial fibroblast in co-culture model.

\section{Abbreviations}

AF Atrial fibrillation

BAT Brown adipose tissue

CAD Coronary artery disease

CVD Cardiovascular diseases

DM Diabetes mellitus

ETA Epicardial adipose tissue

FGFR1 Fibroblast growth factor receptor 1

FGF21 Fibroblast growth factor

HG High glucose

IL-6 Interleukin 6

KO Knockout

LG Low glucose

MCP-1 Monocyte chemoattractant protein 1

MiRNA MicroRNA

PPARY Peroxisome proliferator-activated receptor gamma

STZ Streptozotocin

TGF- $\boldsymbol{\beta}$ Transforming growth factor-beta

TNF-a Tumor necrosis factor alpha

UCP-1 Uncoupling protein-1 
UTR Untranslated region

WAT White adipose tissue

WT Wild type

a-SMA Alpha-smooth muscle actin

\section{Declarations}

\section{Ethics approval and consent to participate}

All animal procedures were performed in accordance with the Guide of US National Institutes of Health for the Care and Use of Laboratory Animals and were approved by the Institutional Animal Care and Use Committee at Shanghai ninth people's hospital of Shanghai Jiaotong University School of Medicine, China. The study of patients was approved by the Research Ethics Committee of Shanghai ninth people's hospital of Shanghai Jiaotong University, China. Written informed consent was obtained from all of the patients enrolled.

\section{Consent for publication}

Not applicable.

\section{Availability of data and materials}

Data sharing is not applicable to this article as no datasets were generated or analysed during the current study.

\section{Competing interests}

The authors declare that they have no competing interests.

\section{Funding}

This work was supported by the National Natural Science Foundation of China (Grant No. 81670293).

\section{Authors' contributions}

JG conducted the study, collected the data, analysed the data, and wrote the manuscript. JAP and JYY contributed to the cell experiments and molecular biology experiments. $\mathrm{HL}$ contributed to the animal experiment, HLZ collected the data of patients and reviewed/edited the manuscript. JFZ and CQW designed the study, contributed to the discussion, and edited the manuscript. All authors read and approved the final manuscript.

\section{Acknowledgements}




\section{References}

1. Eid S, Sas KM, Abcouwer SF, Feldman EL, Gardner TW, Pennathur S, et al. New insights into the mechanisms of diabetic complications: role of lipids and lipid metabolism. Diabetologia. 2019;62(9):1539-49.

2. Forbes JM, Cooper ME. Mechanisms of diabetic complications. Physiol Rev. 2013:93(1):137-88.

3. January CT, Wann LS, Calkins H, Chen LY, Cigarroa JE, Cleveland JC, et al. 2019 AHA/ACC/HRS focused update of the 2014 AHA/ACC/HRS guideline for the management of patients with atrial fibrillation: A Report of the American College of Cardiology/American Heart Association Task Force on Clinical Practice Guidelines and the Heart Rhythm Society. Heart Rhythm. 2019;16(8):e66-93.

4. Dublin S, Glazer NL, Smith NL, Psaty BM, Lumley T, Wiggins KL, et al. Diabetes mellitus, glycemic control, and risk of atrial fibrillation. J Gen Intern Med. 2010;25(8):853-8.

5. Schoen T, Pradhan AD, Albert CM, Conen D. Type 2 diabetes mellitus and risk of incident atrial fibrillation in women. J Am Coll Cardiol. 2012;60(15):1421-8.

6. Ostgren CJ, Merlo J, Rastam L, Lindblad U. Atrial fibrillation and its association with type 2 diabetes and hypertension in a Swedish community. Diabetes Obes Metab. 2004;6(5):367-74.

7. Bohne LJ, Johnson D, Rose RA, Wilton SB, Gillis A. The Association Between Diabetes Mellitus and Atrial Fibrillation: Clinical and Mechanistic Insights. Front Physiol. 2019;10:135.

8. Schindler TH. Epicardial adipose tissue: A new cardiovascular risk marker? Int J Cardiol. 2019;278:263-4.

9. Ansaldo AM, Montecucco F, Sahebkar A, Dallegri F, Carbone F. Epicardial adipose tissue and cardiovascular diseases. Int J Cardiol. 2019;278:254-60.

10. Abe I, Teshima Y, Kondo H, Kaku H, Kira S, Ikebe Y, et al. Association of fibrotic remodeling and cytokines/chemokines content in epicardial adipose tissue with atrial myocardial fibrosis in patients with atrial fibrillation. Heart rhythm. 2018;15(11):1717-27.

11. Oba K, Maeda M, Maimaituxun G, Yamaguchi S, Arasaki O, Fukuda D, et al. Effect of the Epicardial Adipose Tissue Volume on the Prevalence of Paroxysmal and Persistent Atrial Fibrillation. Circ J. 2018;82(7):1778-87.

12. Dozio E, Vianello E, Briganti S, Fink B, Malavazos AE, Scognamiglio ET, et al. Increased reactive oxygen species production in epicardial adipose tissues from coronary artery disease patients is associated with brown-to-white adipocyte trans-differentiation. Int J Cardiol. 2014;174(2):413-4.

13. Grunewald ZI, Winn NC, Gastecki ML, Woodford ML, Ball JR, Hansen SA, et al. Removal of interscapular brown adipose tissue increases aortic stiffness despite normal systemic glucose metabolism in mice. Am J Physiol Regul Integr Comp Physiol. 2018;314(4):R584-97.

14. Kaisanlahti A, Glumoff T. Browning of white fat: agents and implications for beige adipose tissue to type 2 diabetes. J Physiol Biochem. 2019;75(1):1-10. 
15. Kharitonenkov A, Shiyanova TL, Koester A, Ford AM, Micanovic R, Galbreath EJ, et al. FGF-21 as a novel metabolic regulator. J Clin Invest. 2005;115(6):1627-35.

16. Nishimura T, Nakatake Y, Konishi M, Itoh N. Identification of a novel FGF, FGF-21, preferentially expressed in the liver. Biochim Biophys Acta. 2000;1492(1):203-6.

17. Fisher FM, Kleiner S, Douris N, Fox EC, Mepani RJ, Verdeguer F, et al. FGF21 regulates PGC-1alpha and browning of white adipose tissues in adaptive thermogenesis. Genes Dev. 2012;26(3):271-81.

18. Hondares E, Iglesias R, Giralt A, Gonzalez FJ, Giralt M, Mampel T, et al. Thermogenic activation induces FGF21 expression and release in brown adipose tissue. J Biol Chem. 2011;286(15):1298390.

19. Bartel DP. MicroRNAs: target recognition and regulatory functions. Cell. 2009;136(2):215-33.

20. Zhou Q, Maleck C, von Ungern-Sternberg SNI, Neupane B, Heinzmann D, Marquardt J, et al: Circulating MicroRNA-21 Correlates With Left Atrial Low-Voltage Areas and Is Associated With Procedure Outcome in Patients Undergoing Atrial Fibrillation Ablation. Circ Arrhythm Electrophysiol. 2018;11(6):e006242.

21. Huang Z, Chen XJ, Qian C, Dong Q, Ding D, Wu QF, et al. Signal Transducer and Activator of Transcription 3/MicroRNA-21 Feedback Loop Contributes to Atrial Fibrillation by Promoting Atrial Fibrosis in a Rat Sterile Pericarditis Model. Circ Arrhythm Electrophysiol. 2016;9(7).

22. Adam O, Lohfelm B, Thum T, Gupta SK, Puhl SL, Schafers HJ, et al. Role of miR-21 in the pathogenesis of atrial fibrosis. Basic Res Cardiol. 2012;107(5):278.

23. Kim SW, Choi JH, Mukherjee R, Hwang KC, Yun JW. Proteomic identification of fat-browning markers in cultured white adipocytes treated with curcumin. Mol Cell Biochem. 2016;415(1-2):51-66.

24. Gu J, Liu X, Wang QX, Guo M, Liu F, Song ZP, et al. Beneficial effects of pioglitazone on atrial structural and electrical remodeling in vitro cellular models. J Mol Cell Cardiol. 2013;65:1-8.

25. 2. Classification and Diagnosis of Diabetes. Diabetes care. 2016;39 Suppl 1:S13-22.

26. January CT, Wann LS, Alpert JS, Calkins H, Cigarroa JE, Cleveland JC, et al. 2014 AHA/ACC/HRS guideline for the management of patients with atrial fibrillation: a report of the American College of Cardiology/American Heart Association Task Force on Practice Guidelines and the Heart Rhythm Society. J Am Coll Cardiol. 2014;64(21):e1-76.

27. Serban RC, Scridon A. Data Linking Diabetes Mellitus and Atrial Fibrillation-How Strong Is the Evidence? From Epidemiology and Pathophysiology to Therapeutic Implications. Can J Cardiol. 2018;34(11):1492-502.

28. Fu H, Li G, Liu C, Li J, Wang X, Cheng L, et al. Probucol prevents atrial remodeling by inhibiting oxidative stress and TNF-alpha/NF-kappaB/TGF-beta signal transduction pathway in alloxaninduced diabetic rabbits. J Cardiovasc Electrophysiol. 2015;26(2):211-22.

29. Fiaschi T, Magherini F, Gamberi T, Lucchese G, Faggian G, Modesti A, et al. Hyperglycemia and angiotensin II cooperate to enhance collagen I deposition by cardiac fibroblasts through a ROSSTAT3-dependent mechanism. Biochim Biophys Acta. 2014;1843(11):2603-10. 
30. Schotten U, Dobrev D, Platonov PG, Kottkamp H, Hindricks G. Current controversies in determining the main mechanisms of atrial fibrillation. J Intern Med. 2016;279(5):428-38.

31. Kato T, Yamashita T, Sekiguchi A, Tsuneda T, Sagara K, Takamura M, et al. AGEs-RAGE system mediates atrial structural remodeling in the diabetic rat. J Cardiovasc Electrophysiol 2008;19(4):41520.

32. Singh VP, Le B, Khode R, Baker KM, Kumar R. Intracellular angiotensin II production in diabetic rats is correlated with cardiomyocyte apoptosis, oxidative stress, and cardiac fibrosis. Diabetes. 2008;57(12):3297-306.

33. Li B, Pan Y, Li X. Type 2 Diabetes Induces Prolonged P-wave Duration without Left Atrial Enlargement. J Korean Med Sci. 2016;31(4):525-34.

34. Toblli JE, Cao G, DeRosa G, Forcada P. Reduced cardiac expression of plasminogen activator inhibitor 1 and transforming growth factor beta1 in obese Zucker rats by perindopril. Heart. 2005;91(1):80-6.

35. Rawal S, Munasinghe PE, Nagesh PT, Lew JKS, Jones GT, Williams MJA, et al. Down-regulation of miR-15a/b accelerates fibrotic remodelling in the Type 2 diabetic human and mouse heart. Clin Sci (Lond). 2017;131(9):847-63.

36. Al Chekakie MO, Welles CC, Metoyer R, Ibrahim A, Shapira AR, Cytron J, et al. Pericardial fat is independently associated with human atrial fibrillation. J Am Coll Cardiol. 2010;56(10):784-8.

37. Batal O, Schoenhagen P, Shao M, Ayyad AE, Van Wagoner DR, Halliburton SS, et al. Left atrial epicardial adiposity and atrial fibrillation. Circ Arrhythm Electrophysiol. 2010;3(3):230-6.

38. Mirolo A, Viart G, Savoure A, Godin B, Raitiere O, Eltchaninoff H, et al. Epicardial fat thickness predicts atrial fibrillation recurrence after a first pulmonary vein isolation procedure using a secondgeneration cryoballoon. Arch Cardiovasc Dis. 2019;112(5):314-22.

39. Zghaib T, Ipek EG, Zahid S, Balouch MA, Misra S, Ashikaga H, et al. Association of left atrial epicardial adipose tissue with electrogram bipolar voltage and fractionation: Electrophysiologic substrates for atrial fibrillation. Heart Rhythm. 2016;13(12):2333-9.

40. Rosito GA, Massaro JM, Hoffmann U, Ruberg FL, Mahabadi AA, Vasan RS, et al. Pericardial fat, visceral abdominal fat, cardiovascular disease risk factors, and vascular calcification in a community-based sample: the Framingham Heart Study. Circulation. 2008;117(5):605-13.

41. Noyes AM, Dua K, Devadoss R, Chhabra L. Cardiac adipose tissue and its relationship to diabetes mellitus and cardiovascular disease. World J Diabetes. 2014; 5(6):868-76.

42. Levelt E, Pavlides M, Banerjee R, Mahmod M, Kelly C, Sellwood J, et al. Ectopic and Visceral Fat Deposition in Lean and Obese Patients With Type 2 Diabetes. J Am Coll Cardiol. 2016, 68(1):53-63.

43. Haemers P, Hamdi H, Guedj K, Suffee N, Farahmand P, Popovic N, et al. Atrial fibrillation is associated with the fibrotic remodelling of adipose tissue in the subepicardium of human and sheep atria. Eur Heart J. 2017;38(1):53-61.

44. Mahajan R, Lau DH, Brooks AG, Shipp NJ, Manavis J, Wood JP, et al. Electrophysiological, Electroanatomical, and Structural Remodeling of the Atria as Consequences of Sustained Obesity. J 
Am Coll Cardiol. 2015;66(1):1-11.

45. Friedman DJ, Wang N, Meigs JB, Hoffmann U, Massaro JM, Fox CS, et al. Pericardial fat is associated with atrial conduction: the Framingham Heart Study. J Am Heart Assoc. 2014;3(2):e000477.

46. Berbee JF, Boon MR, Khedoe PP, Bartelt A, Schlein C, Worthmann A, et al. Brown fat activation reduces hypercholesterolaemia and protects from atherosclerosis development. Nat Commun. 2015;6:6356.

47. Fu T, Seok S, Choi S, Huang Z, Suino-Powell K, Xu HE, et al. MicroRNA 34a inhibits beige and brown fat formation in obesity in part by suppressing adipocyte fibroblast growth factor 21 signaling and SIRT1 function. Mol Cell Biol. 2014;34(22):4130-42.

48. Inagaki T, Dutchak P, Zhao G, Ding X, Gautron L, Parameswara V, et al. Endocrine regulation of the fasting response by PPARalpha-mediated induction of fibroblast growth factor 21. Cell Metab. 2007;5(6):415-25.

49. Dutchak PA, Katafuchi T, Bookout AL, Choi JH, Yu RT, Mangelsdorf DJ, et al. Fibroblast growth factor21 regulates PPARgamma activity and the antidiabetic actions of thiazolidinediones. Cell. 2012;148(3):556-67.

50. Canto C, Auwerx J. Cell biology. FGF21 takes a fat bite. Science. 2012;336(6082):675-6.

51. Lee P, Linderman JD, Smith S, Brychta RJ, Wang J, Idelson C, et al. Irisin and FGF21 are cold-induced endocrine activators of brown fat function in humans. Cell Metab. 2014;19(2):302-9.

52. Distel E, Penot G, Cadoudal T, Balguy I, Durant S, Benelli C. Early induction of a brown-like phenotype by rosiglitazone in the epicardial adipose tissue of fatty Zucker rats. Biochimie. 2012;94(8):1660-7.

53. Moyers JS, Shiyanova TL, Mehrbod F, Dunbar JD, Noblitt TW, Otto KA, et al. Molecular determinants of FGF-21 activity-synergy and cross-talk with PPARgamma signaling. J Cell Physiol. 2007;210(1):16.

54. Muise ES, Azzolina B, Kuo DW, El-Sherbeini M, Tan Y, Yuan X, et al. Adipose fibroblast growth factor 21 is up-regulated by peroxisome proliferator-activated receptor gamma and altered metabolic states. Mol Pharmacol. 2008;74(2):403-12.

55. Qiang L, Accili D. FGF21 and the second coming of PPARgamma. Cell. 2012;148(3):397-8.

56. Chen J, Hu J, Liu H, Xiong Y, Zou Y, Huang W, et al. FGF21 Protects the Blood-Brain Barrier by Upregulating PPARgamma via FGFR1/beta-klotho after Traumatic Brain Injury. J Neurotrauma. 2018;35(17):2091-103.

57. Tao H, Zhang M, Yang JJ, Shi KH. MicroRNA-21 via Dysregulation of WW Domain-Containing Protein 1 Regulate Atrial Fibrosis in Atrial Fibrillation. Heart Lung Circ. 2018;27(1):104-13.

58. Cao W, Shi P, Ge JJ. miR-21 enhances cardiac fibrotic remodeling and fibroblast proliferation via CADM1/STAT3 pathway. BMC Cardiovasc Disord. 2017;17(1):88.

59. Trajkovski M, Ahmed K, Esau CC, Stoffel M. MyomiR-133 regulates brown fat differentiation through Prdm16. Nat Cell Biol. 2012;14(12):1330-5. 
60. Yin H, Pasut A, Soleimani VD, Bentzinger CF, Antoun G, Thorn S, et al. MicroRNA-133 controls brown adipose determination in skeletal muscle satellite cells by targeting Prdm16. Cell Metab. 2013;17(2):210-24.

61. Chen Y, Siegel F, Kipschull S, Haas B, Frohlich H, Meister G, et al. miR-155 regulates differentiation of brown and beige adipocytes via a bistable circuit. Nat Commun. 2013;4:1769.

62. Venteclef N, Guglielmi V, Balse E, Gaborit B, Cotillard A, Atassi F, et al. Human epicardial adipose tissue induces fibrosis of the atrial myocardium through the secretion of adipo-fibrokines. Eur Heart J. 2015;36(13):795-805a.

63. Chilukoti RK, Giese A, Malenke W, Homuth G, Bukowska A, Goette A, et al. Atrial fibrillation and rapid acute pacing regulate adipocyte/adipositas-related gene expression in the atria. Int $\mathrm{J}$ Cardiol. 2015;187:604-13.

\section{Tables}

Table 1. Demographic and clinical characteristics of enrolled patients

\begin{tabular}{cccccc}
\hline \hline & $\begin{array}{c}\text { Control } \\
(\mathrm{n}=20)\end{array}$ & $\begin{array}{c}\mathrm{DM} \\
(\mathrm{n}=20)\end{array}$ & $\begin{array}{c}\mathrm{DM}+\mathrm{AF} \\
(\mathrm{n}=20)\end{array}$ & $\begin{array}{c}\text { AF } \\
(\mathrm{n}=20)\end{array}$ & P value \\
\hline age, y & $64.7 \pm 8.8$ & $64.1 \pm 7.8$ & $65.2 \pm 5.3$ & $65.1 \pm 5.8$ & 0.964 \\
male & $11(55)$ & $14(70)$ & $12(60)$ & $15(75)$ & 0.532 \\
$\mathrm{BMI}, \mathrm{kg} / \mathrm{m} 2$ & $25.1 \pm 2.9$ & $24.5 \pm 1.6$ & $24.6 \pm 2.3$ & $25.8 \pm 1.7$ & 0.295 \\
$\mathrm{LAD}, \mathrm{mm}$ & $39.6 \pm 2.3$ & $39.8 \pm 2.1$ & $42.1 \pm 2.6$ & $41.8 \pm 2.2$ & 0.001 \\
$\mathrm{SBP}, \mathrm{mmHg}$ & $126.8 \pm 11.7$ & $128.0 \pm 11.5$ & $132.3 \pm 14.6$ & $128.3 \pm 11.3$ & 0.528 \\
$\mathrm{DBP}, \mathrm{mmHg}$ & $75.2 \pm 5.3$ & $74.0 \pm 6.6$ & $75.9 \pm 6.4$ & $76.6 \pm 8.4$ & 0.671 \\
LVEF, (\%) & $63.5 \pm 4.7$ & $63.5 \pm 5.2$ & $62.8 \pm 4.6$ & $62.9 \pm 3.8$ & 0.918 \\
hypertension & $14(70)$ & $15(75)$ & $14(70)$ & $15(75)$ & 0.969 \\
dyslipidemia & $5(25)$ & $5(25)$ & $6(30)$ & $7(35)$ & 0.880 \\
beta-blockers & $4(20)$ & $6(30)$ & $8(40)$ & $7(35)$ & 0.565 \\
anticolagulant & 0 & 0 & $5(25)$ & $3(15)$ & 0.017 \\
ACEI/ARB & $11(55)$ & $13(65)$ & $13(65)$ & $10(50)$ & 0.769 \\
statin & $3(15)$ & $4(20)$ & $3(15)$ & $2(10)$ & 0.972 \\
\hline \hline
\end{tabular}

Data are presented as mean \pm SD or number (\%) of subjects. DM: diabetes mellitus; $\mathrm{AF}$ : atrial fibrillation; BMI: body mass index; LAD: left atrium diameter; SBP: systolic blood pressure; DBP: diastolic blood pressure; LVEF: left ventricular ejection fraction;; ACEI/ARB: angiotensin converting enzyme inhibitor/angiotensin II receptor blocker.

\section{Figures}



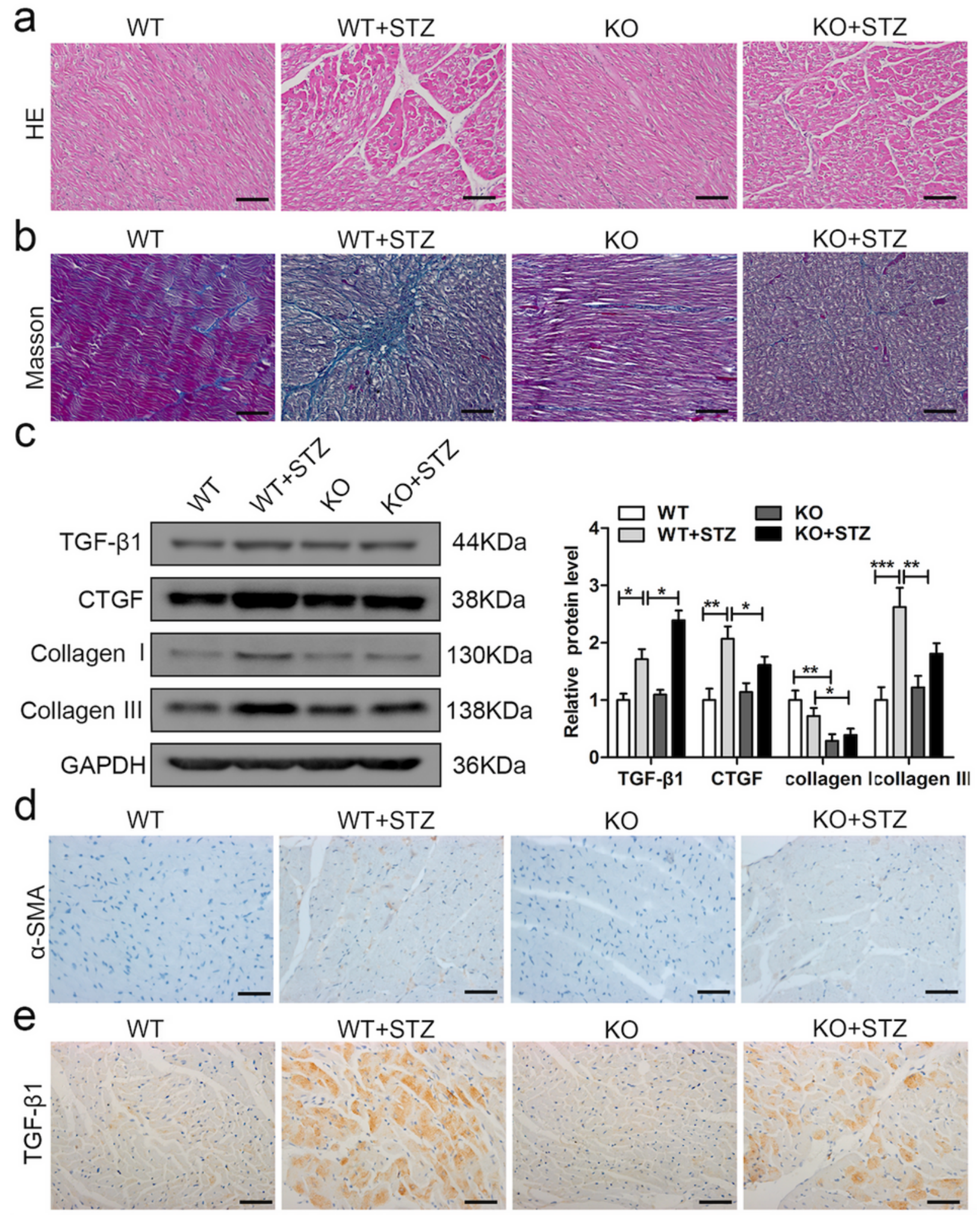

Figure 2

Atrial fibrosis was analyzed 3 months after the modeling in WT and miR-21 KO mice $(n=6)$. a. H\&E staining of atrial myocardial tissue samples $(\times 400$; scale bar, $50 \mu \mathrm{m})$. b. Masson's staining of atrial myocardial tissue samples ( $\times 400$; scale bar, $50 \mu \mathrm{m})$. c. TGF- $\beta 1$, CTGF, Collagen I and collagen III expression in atrial myocardial tissue were analyzed by western blotting and quantitative by Image $\mathrm{J}$. $\mathrm{d}$ 
and e. a-SMA and TGF- $\beta 1$ expression in myocardial tissue were analyzed by immunohistochemistry (IHC) ( $\times 400$; scale bar, $50 \mu \mathrm{m})$.

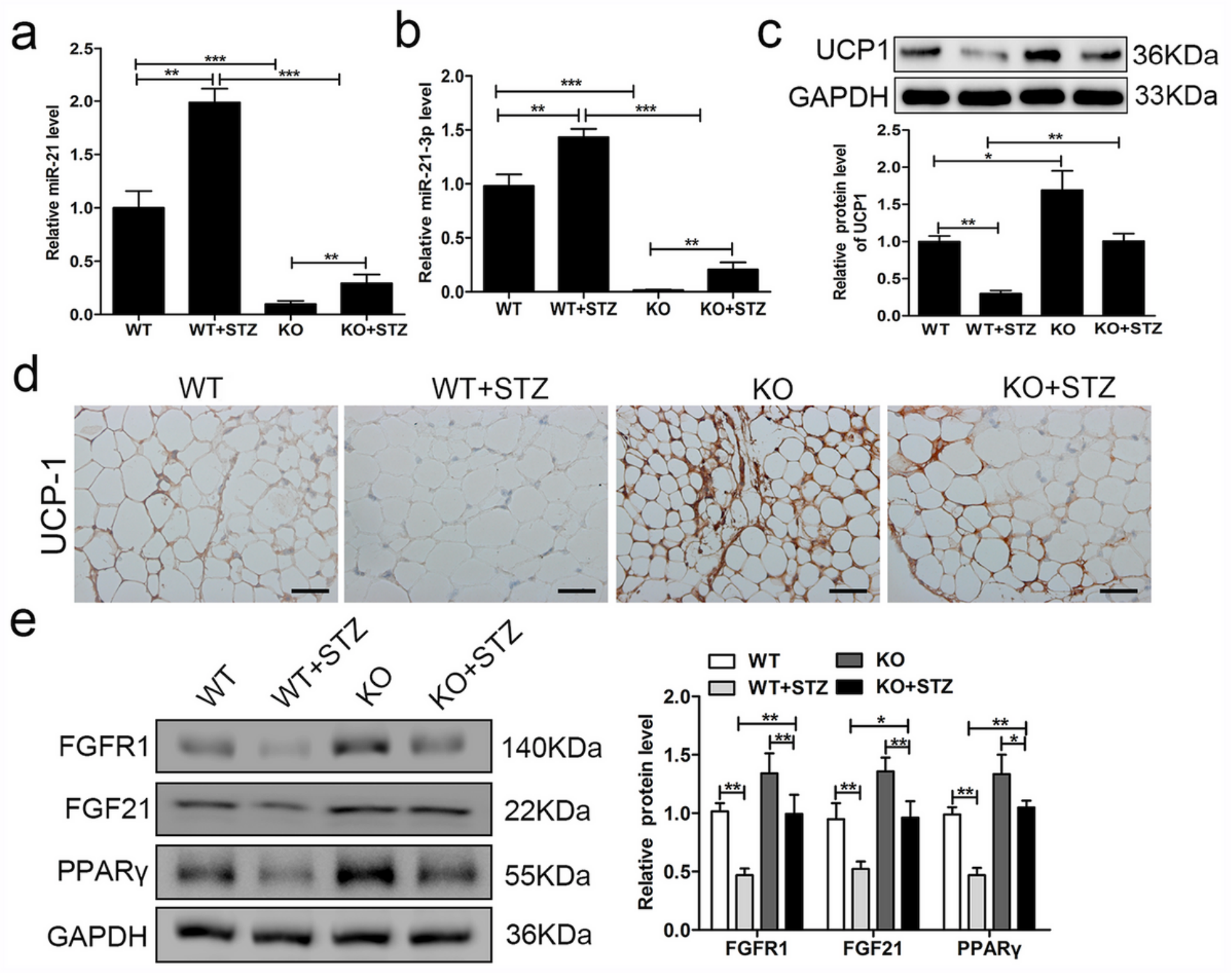

Figure 3

Browning of pericardial adipose tissue were analyzed 3 months after the modeling in WT and miR-21 KO mice $(n=6)$. $a$ and $b$. The relative miR-21 and miR-21-3p expression were detected by qRT-PCR in pericardial adipose tissue. c. Western blotting was used to analyze UCP1 expression and quantitative by Image J. d. UCP1 expression was analyzed by immunohistochemistry ( $\times 400$; scale bar, $50 \mu \mathrm{m})$. e. Western blotting was used to analyze FGFR1, FGF21, PPARy expression in pericardial adipose tissue and quantitative by Image $J .{ }^{*} P<0.05,{ }^{*} P<0.01$ and $* * * P<0.001$. 

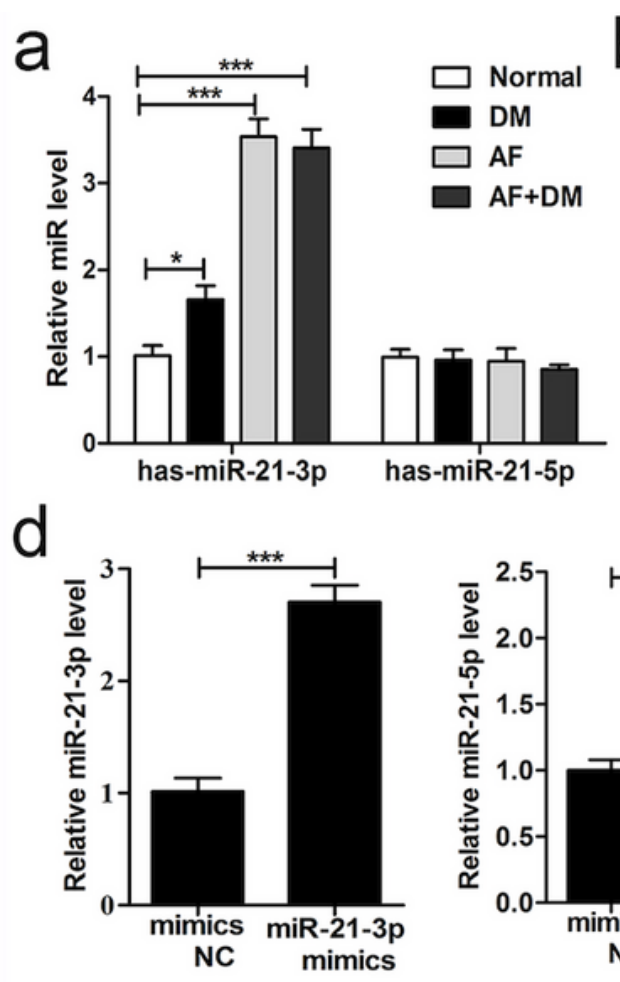

b

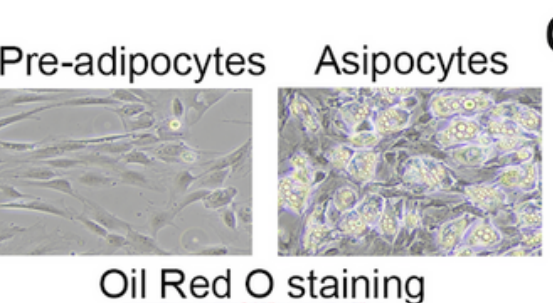

C
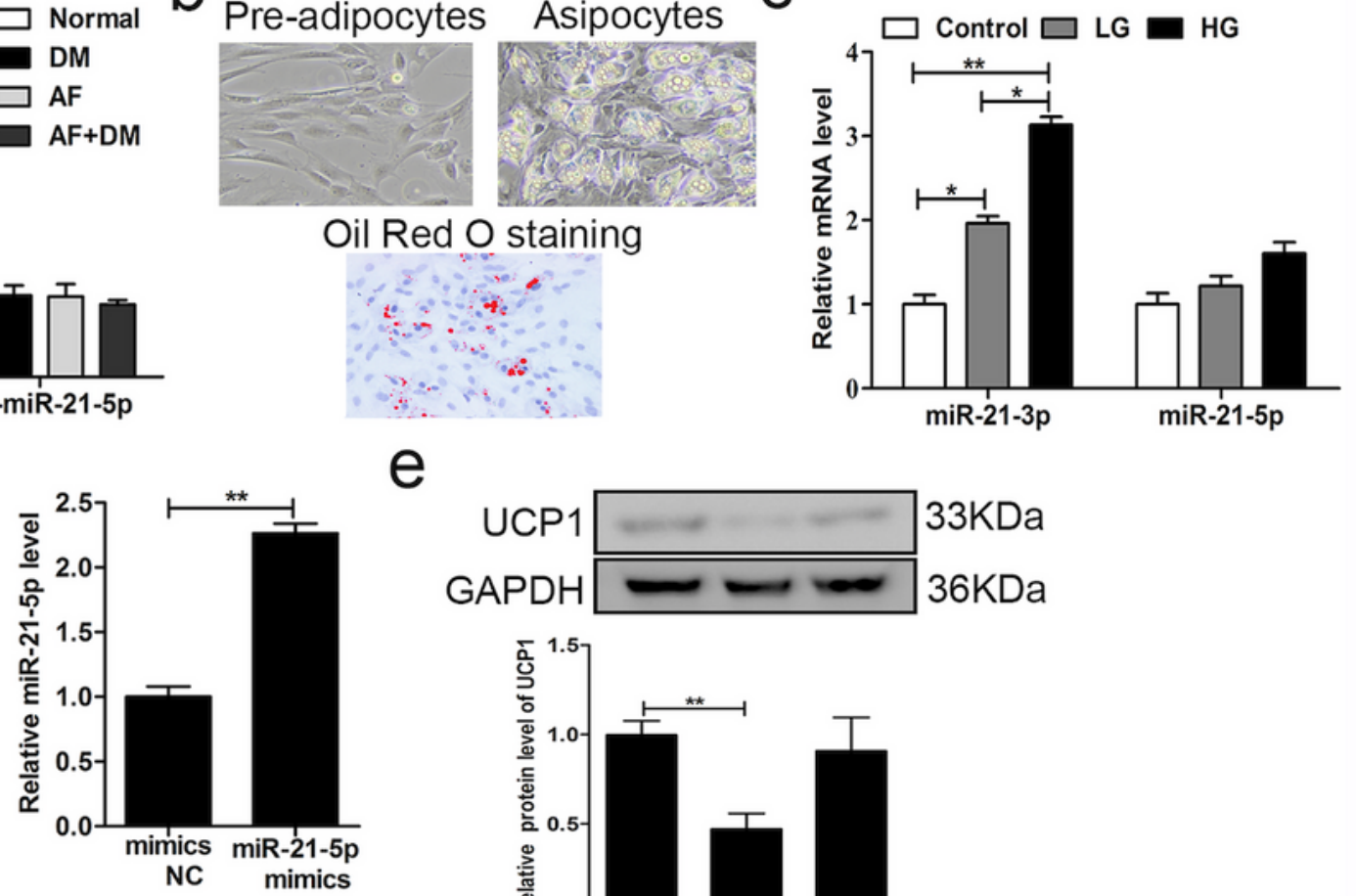

e
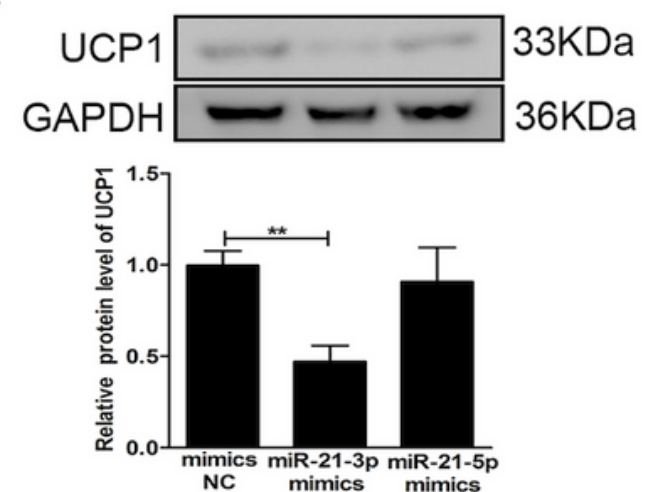

f
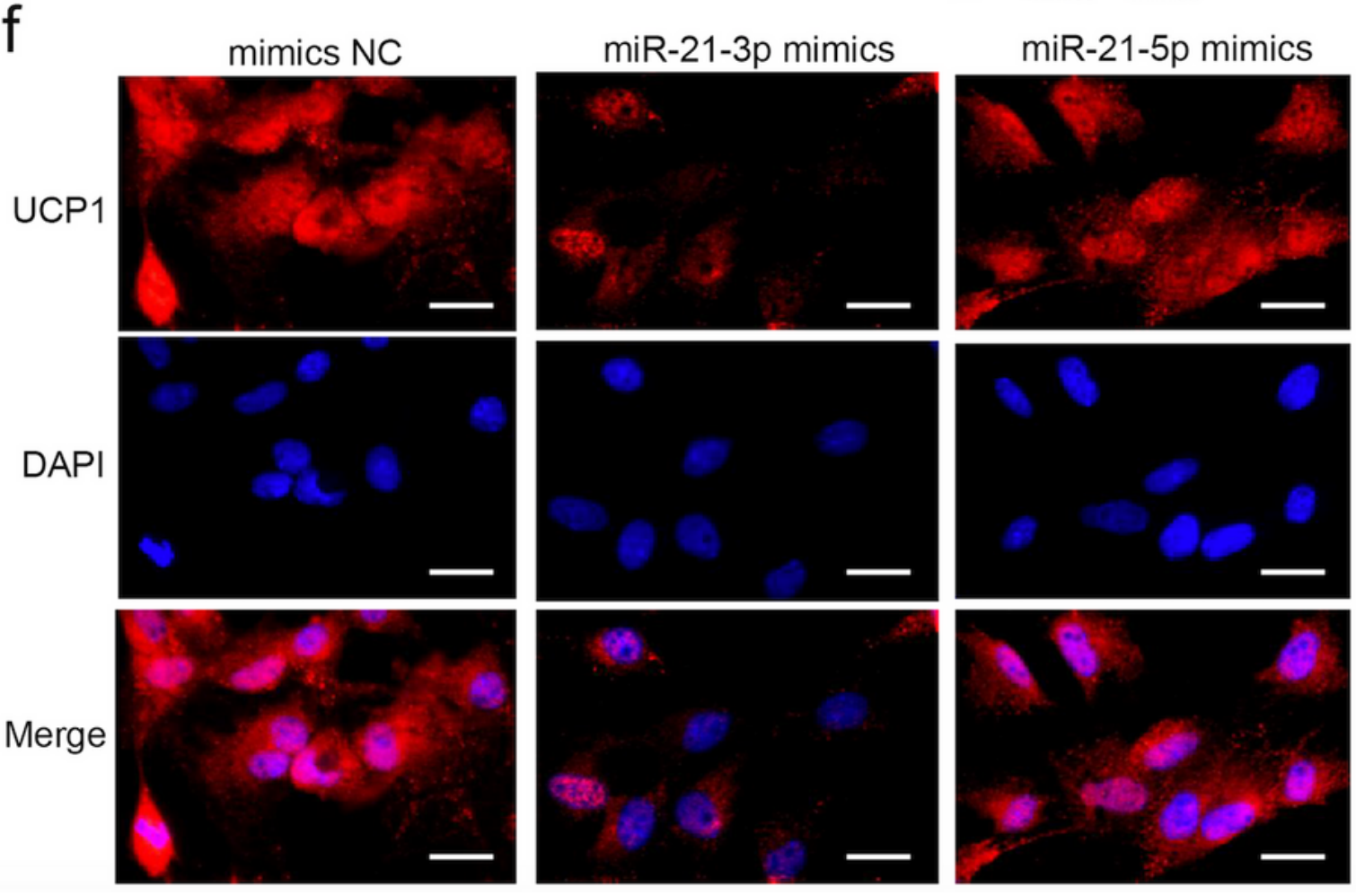

\section{Figure 5}

MiR-21-3p plays a major role in browning of white fat. a. The relative levels of hsa-miR-21-3p and hsamiR-21-5p in the serum of different patients were detected by qRT-PCR $(n=20)$. b. Adipocytic differentiation of pre-adipocytes isolated from miR-21 KO mice and Oil Red 0 staining of mature adipocytes after differentiation induction ( $\times 400$, scale bar, $50 \mu \mathrm{m})$. c. The relative miR-21-3p and miR-21$5 p$ mRNA expression in pre-adipocytes extracted from WT mice after treated with low glucose (LG) (5.5 
$\mathrm{mM}$ ) and high glucose $(\mathrm{HG})(30 \mathrm{mM})$ for $72 \mathrm{~h}$ were determined by qRT-PCR. $\mathrm{d}$. The extent of miR-21-3p and miR-21-5p overexpression in pre-adipocytes extracted from miR-21 KO mice were detected by qRTPCR. e. UCP1 expression was detected by western blotting and quantitative by Image J. f. UCP1 expression was detected by immunofluorescence $(\times 400$, scale bar, $50 \mu \mathrm{m})$. UCP1 (red) are shown; nuclei are stained by DAPI (blue). Mean \pm SD of three independent experiments. ${ }^{*}<0.05,{ }^{*} P<0.01$ and $* * * P<0.001$.

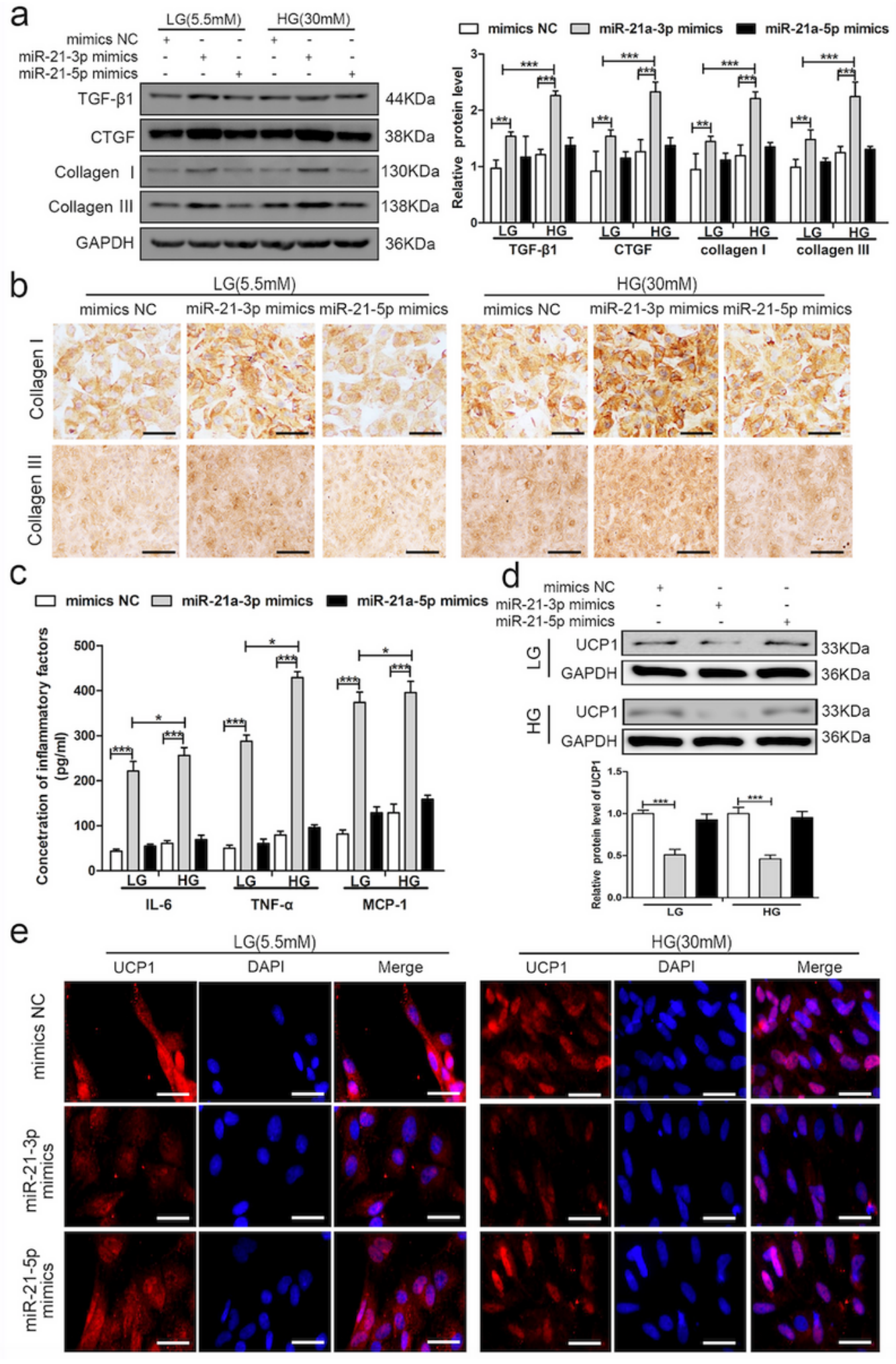

Figure 8 
MiR-21-3p inhibits browning of white fat to promote high glucose-induced myocardial fibrosis. Preadipocytes from miR-21 KO mice transfected with mimics NC, miR-21-3p mimics or miR-21-5p mimics and then induced to differentiate into mature adipocytes. Mature adipocytes co-culture with atrial fibroblasts from WT mice treated with low glucose (LG) $(5.5 \mathrm{mM})$ and high glucose (HG) $(30 \mathrm{mM})$ for 72 h. a. TGF- $\beta 1$, CTGF, Collagen I and collagen III expression in atrial fibroblasts were analyzed by western blotting and quantitative by Image J. b. Collagen I and collagen III expression in atrial fibroblasts were analyzed by immunohistochemistry $(\times 200$; scale bar, $100 \mu \mathrm{m})$. c. ELISA was used to analyze TNF-aIIL-60 MCP-1 concentration in co-culture supernatants. $d$. Western blotting was used to analyze UCP1 expression in mature adipocytes and quantitative by Image J. e. UCP1 expression in mature adipocytes was detected by immunofluorescence $(\times 400$; scale bar, $50 \mu \mathrm{m})$. UCP1 (red) are shown; nuclei are stained by DAPI (blue). Mean \pm SD of three independent experiments. ${ }^{*} P<0.05$, ${ }^{\star *} P<0.01$ and ${ }^{\star *} * P<0.001$. 


\section{a}

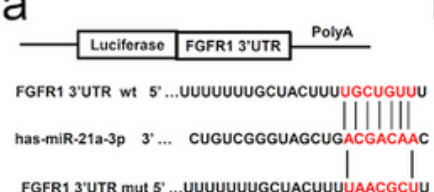

b
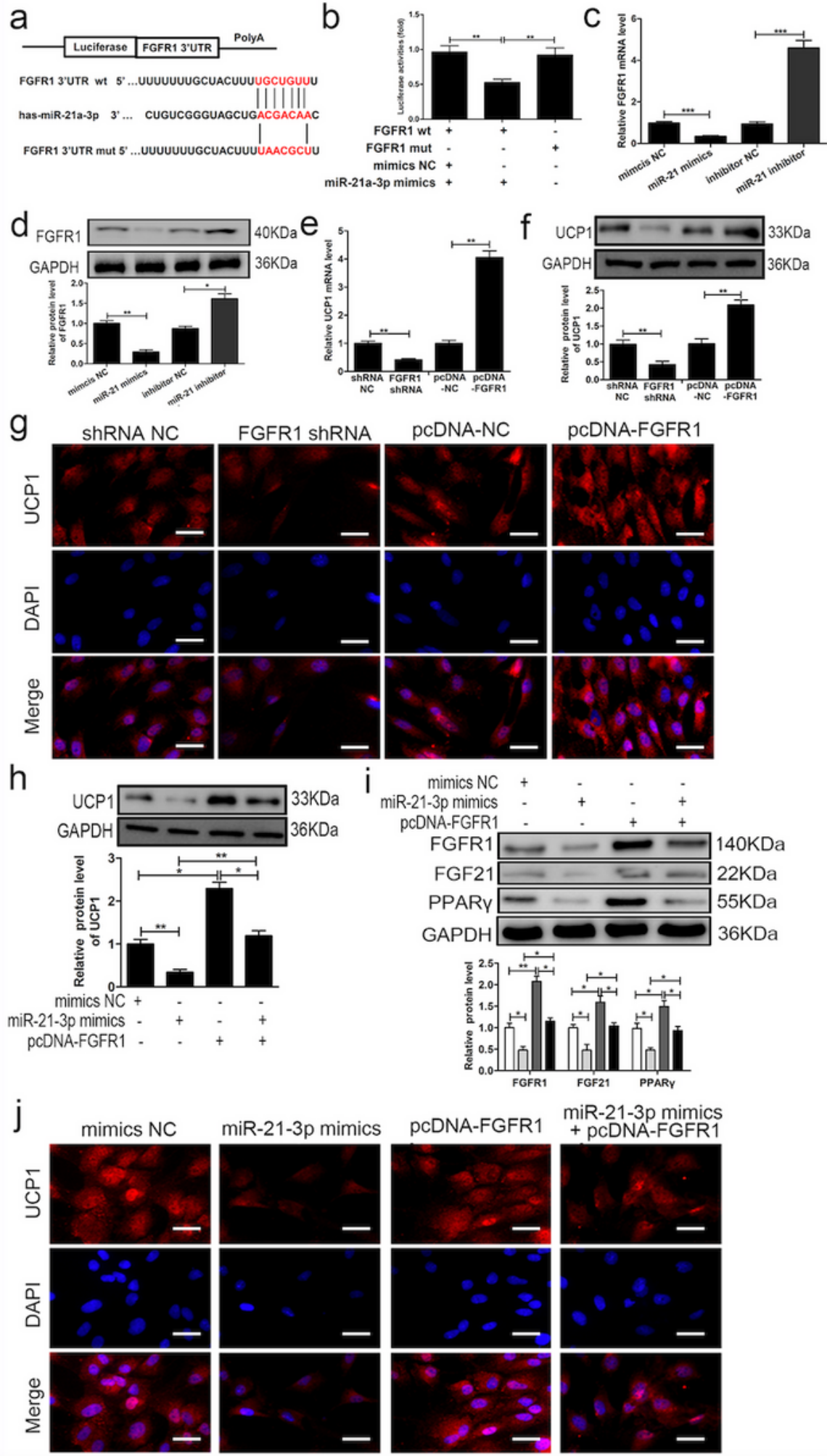

miR-21-3p mimics

+ pcDNA-FGFR1

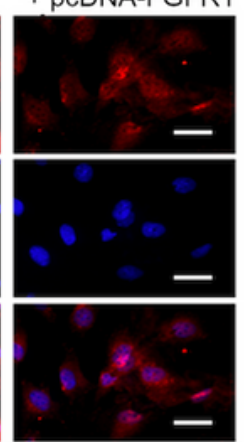

\section{Figure 10}

MiR-21-3p participates in browning of white fat by targeting FGFR1. a. Putative miR-21-3p binding sites in the FGFR1 3'-UTR. b. A luciferase reporter plasmid containing wild-type or mutant FGFR1 was cotransfected into 293 cells with miR-21-3p mimics or mimics control. Luciferase activity was determined at 48h after transfection using the dual-luciferase assay and shown as the relative luciferase activity normalized to Renilla activity. c and d. Pre-adipocytes extracted from WT mice transfected with mimics 
NC, miR-21-3p mimics, inhibitor NC, miR-21-3p inhibitor and then induced to differentiate into mature adipocytes. qRT-PCR and western blotting were determined to analysis FGFR1 expression. e and f. Preadipocytes from WT mice transfected with shRNA NC, FGFR1 shRNA, pcDNA-NC, pcDNA-FGFR1 and then induced to differentiate into mature adipocytes. The relative UCP1 expression were detected by qRT-PCR and western blotting analysis. g. UCP1 expression was detected by immunofluorescence $(\times 400$; scale bar, $50 \mu \mathrm{m})$. $\mathrm{h}$ and $\mathrm{j}$. Pre-adipocytes from miR-21 KO mice transfected with mimics NC, miR-21-3p mimics, pcDNA-FGFR1, miR-21-3p mimics+pcDNA-FGFR1, and then induced to differentiate into mature adipocytes. Western blotting was used to analyze UCP1 expression. i. Western blotting was used to analyze FGFR1, FGF21, PPARy expression and quantitative by Image J. j. UCP1 expression was detected by immunofluorescence ( $\times 400$; scale bar, $50 \mu \mathrm{m})$. UCP1 (red) are shown; nuclei are stained by DAPI (blue). Mean \pm SD of three independent experiments. ${ }^{\star} P<0.05$, ${ }^{\star \star} P<0.01$ and ${ }^{\star \star *} P<0.001$. 


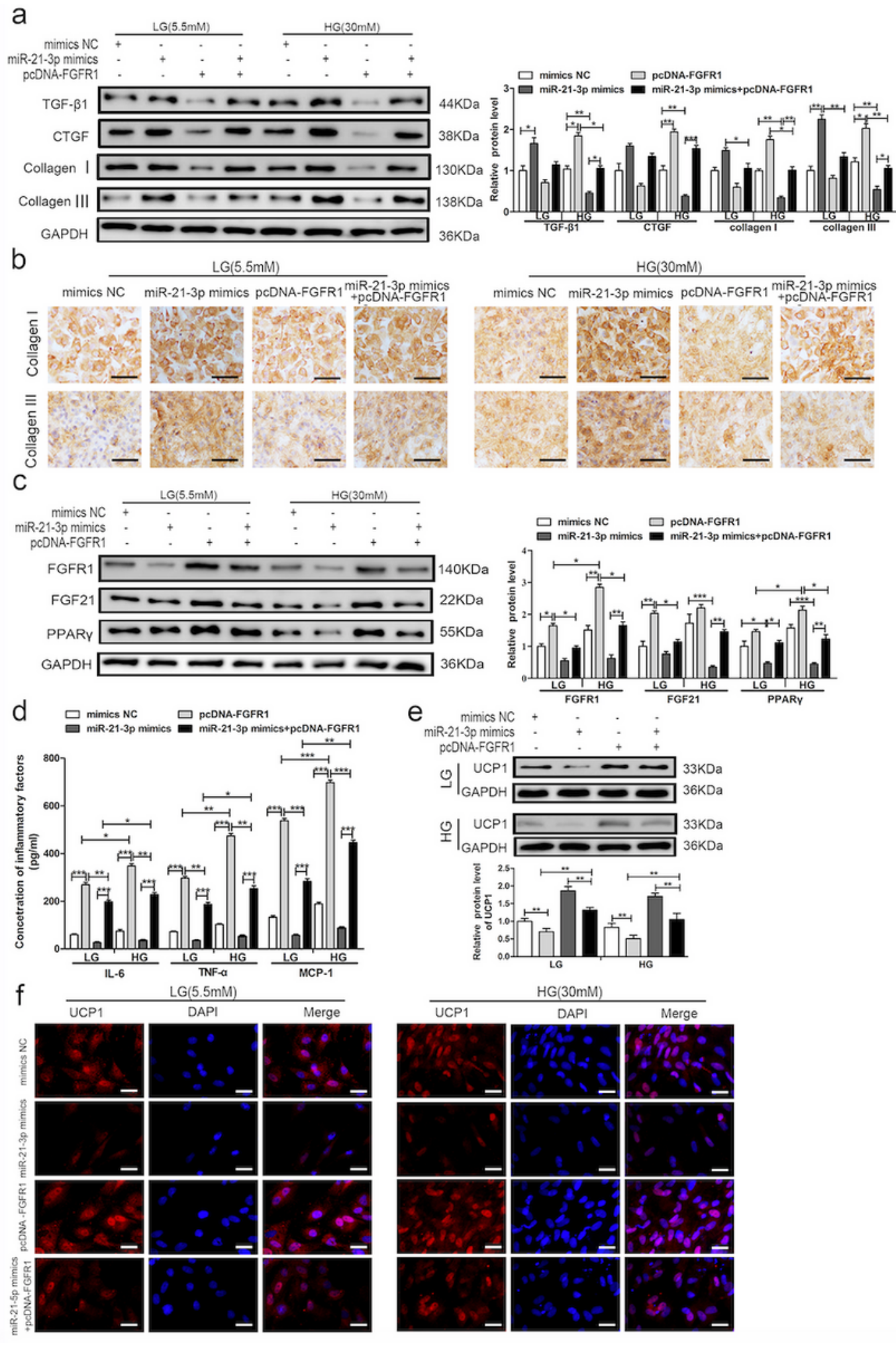

Figure 12

MiR-21-3p regulated fat browning associated protein FGFR1/FGF21/PPARy to promote high glucoseinduced myocardial fibrosis by targeting FGFR1. Pre-adipocytes from miR-21 KO mice transfected with mimics NC, miR-21-3p mimics, pcDNA-FGFR1, miR-21-3p mimics+pcDNA-FGFR1, and then induced to differentiate into mature adipocytes. Mature adipocytes co-culture with atrial fibroblasts from WT mice treated with low glucose (LG) (5.5 mM) and high glucose (HG) (30 mM) for 72 h. a. TGF- $\beta 1$, CTGF, 
Collagen I and collagen III expression in atrial fibroblasts were analyzed by western blotting and quantitative by Image J. b. Collagen I and collagen III expression in atrial fibroblasts were analyzed by immunohistochemistry ( $\times 200$; scale bar, $100 \mu \mathrm{m})$. c. Western blotting was used to analyze FGFR1, FGF21 and PPARY expression in mature adipocytes and quantitative by Image J. d. ELISA was used to analyze TNF-aIIL-6ロMCP-1 concentration in co-culture supernatants. e. Western blotting was used to analyze UCP1 expression in mature adipocytes and quantitative by Image J. f. UCP1 expression in mature adipocytes was detected by immunofluorescence $(\times 400$; scale bar, $50 \mu \mathrm{m})$. UCP1 (red) are shown; nuclei are stained by DAPI (blue). Mean \pm SD of three independent experiments. ${ }^{*} P<0.05,{ }^{* *} P<0.01$ and $\star \star \star P<0.001$.

\section{Supplementary Files}

This is a list of supplementary files associated with this preprint. Click to download.

- Supplementaltable.docx

- Supplementalfigure1.tif

- Supplementaltable.docx

- Supplementalfigure1.tif 